\title{
Estratigrafia do Grupo Bambuí e coberturas fanerozóicas no vale do rio São Francisco, norte de Minas Gerais
}

\author{
Mario Iglesias $^{1}$ \& Alexandre Uhlein ${ }^{2}$
}

\begin{abstract}
Resumo Apresenta-se o resultado do mapeamento geológico regional e de integração de dados geológicos de uma área de $40.000 \mathrm{~km}^{2}$ no norte do Estado de Minas Gerais. Foram mapeados afloramentos de gnaisses arqueanos, pertencentes ao embasamento cristalino, rochas carbonáticas e terrígenas que compõem o Grupo Bambuí, de idade neoproterozóica, arenitos do Grupo Urucuia (Cretáceo) e coberturas recentes. A deposição das formações do Grupo Bambuí na área é resultado da paleogeografia do embasamento e de processos tectônicos. Foram verificadas áreas de embasamento em altos estruturais (Alto de Januária) e depocentros locais na porção sul e leste da área, onde a espessura do Grupo Bambuí é substancialmente maior. A Formação Sete Lagoas, representada por sucessão plataformal rasa, constituída por calcários e dolomitos, aflora, exclusivamente, na margem esquerda do rio São Francisco. As unidades médias do Grupo Bambuí, formações Serra de Santa Helena (siltitos, folhelhos e lentes de calcário escuro) e Lagoa do Jacaré (calcários oolíticos/intraclásticos, siltitos e margas), apresentam uma ampla distribuição em toda a região. Detalhado estudo petrográfico dos carbonatos da Formação Lagoa do Jacaré na região de Lontra (sul da área) evidenciou uma importante variação faciológica para esta unidade. Já as formações Serra da Saudade (siltitos e folhelhos) e Três Marias (arenitos, arcósios e siltitos) afloram apenas nos extremos leste e sul da área, apresentando depocentros locais, diferenciados das formações inferiores.
\end{abstract}

Palavras-chave: Neoproterozóico, Grupo Bambuí, Minas Gerais, estratigrafia, sedimentação, mapeamento geológico.

\begin{abstract}
Stratigraphy of the Bambui Group and phanerozoic covers at the São Francisco river valley, northern Minas Gerais, Brazil. This work presents the results of extensive geological mapping over $40.000 \mathrm{~km}^{2}$ in northwestern Minas Gerais. Basement rocks (mostly Archean gneiss) crop out locally. The most important rocks ocurring in the study area are: carbonate and terrigenous rocks belonging to the Neoproterozoic Bambuí Group, Cretaceous sandstones of the Urucuia Group and Cenozoic sediments. The distribution of the Bambuí Group in the area is the result of the paleogeography of the basement and also of tectonic processes. Basement exposures were identified in paleo-highs (Alto de Januária) and local depocenters in the southern and eastern portions of the study area. The thickness of the Bambuí Group increases substantially in these areas. The Sete Lagoas Formation, represented by a shallow platform succession, is made up of limestones and dolomites. This unit crops out, exclusively, in the western margin of the São Francisco River. Medium units of the Bambuí Group, Serra de Santa Helena formation (siltstones and dark limestones lenses) and Lagoa do Jacaré formation (oolitic/intraclastic limestones, siltstones and marlstones) are widely distributed in the study area. A detailed petrologic study of carbonates of the Lagoa do Jacaré formation around Lontra region (southern part of the study area) showed an important facies variability for this unit. Serra da Saudade Formation (siltstones and shales) and Três Marias Formation (sandstones, arkoses and siltstones) crop out only in the eastern and southern borders of the study area. Both units present different local depocenters as compared to the lower formations.
\end{abstract}

Keywords: Neoproterozoic, Bambuí Group, Minas Gerais, stratigraphy, sedimentation, geological mapping.

INTRODUÇÃO A região estudada coincide com o extremo norte do Estado de Minas Gerais (Fig. 1). Perfaz um total de $40.000 \mathrm{Km}^{2}$, limitados pelos meridianos $43^{\circ} 19^{\prime} 00^{\prime \prime} \mathrm{W}-45^{\circ} 48^{\prime} 10^{\prime \prime} \mathrm{W}$ e pelos paralelos $14^{\circ} 14^{\prime} 17^{\prime \prime S}$ - 16 $39^{\prime} 36^{\prime \prime} \mathrm{S}$. O presente trabalho tem como objetivo principal apresentar o mapa geológico desta ampla região e contribuir com detalhada descrição das unidades litoestratigráficas do Grupo Bambuí e suas coberturas fanerozóicas, aflorantes no norte do Estado de Minas Gerais.

Através de dissertação de mestrado efetuada no Instituto de Geociências da Universidade Federal de Minas Gerais (Iglesias 2007) foi possível efetuar o mapeamento geológico desta área. O mapeamento geológico, aliado a estudo hidrogeológico regional e epidemiológico, visou estudar anomalias de fluoreto na água

1 - Universidade Federal de Minas Gerais, Instituto de Geociências, Departamento de Geologia, Programa de Pós-Graduação em Geologia Regional, Belo Horizonte (MG), Brasil. E-mail: marioiglesiasmartinez@yahoo.es

2 - Universidade Federal de Minas Gerais, Instituto de Geociências, Departamento de Geologia, Belo Horizonte (MG), Brasil.

E-mail: uhlein@netuno.lcc.ufmg.br 


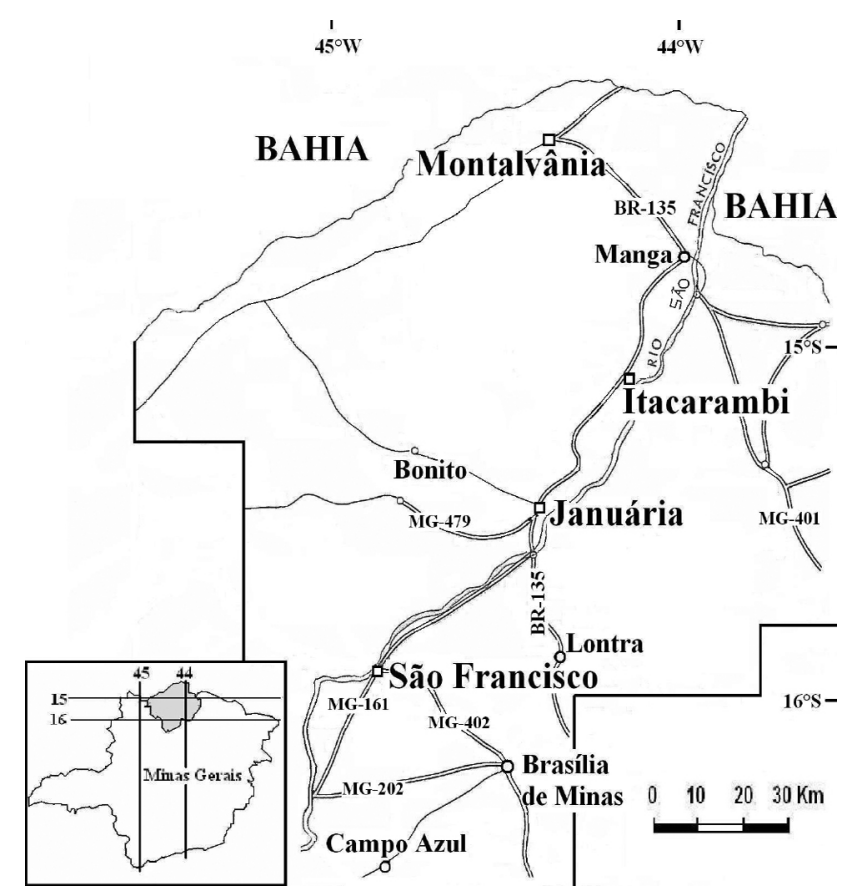

Figura 1 - Localização da área estudada e principais vias de acesso.

subterrânea desta ampla região. As anomalias de flúor na água subterrânea utilizada pela população são relacionadas a inúmeros casos de fluorose dental no norte do Estado de Minas Gerais (Velásquez et al. 2006, Iglesias et al. submetido).

O mapeamento geológico apoiou-se numa integração de dados de projetos anteriores, de escala regional, combinado com a realização, no campo, de seções e perfis regionais e de detalhe. Utilizou-se, também, de análise de imagens de satélite, para estudo estrutural e tectônico (Iglesias 2007).

Este artigo sintetiza as principais conclusões dos trabalhos de mapeamento geológico, assim como a integração de amplo acervo de dados a partir de levantamento bibliográfico. Como resultado desses trabalhos foram identificadas, descritas e mapeadas as formações do Grupo Bambuí e suas coberturas, seguindo critérios litoestratigráficos.

Trabalhos anteriores A maior parte dos estudos geológicos disponíveis sobre a região é resultante dos levantamentos geológicos realizados nas décadas de 1970 e 1980 por instituições governamentais (Metais de Minas Gerais "METAMIG"; Companhia de Pesquisa de Recursos Minerais "CPRM"; Departamento Nacional de Produção Mineral "DNPM"; Fundação Centro Tecnológico de Minas Gerais "CETEC") atuantes, principalmente na Bacia do São Francisco e Alto Paranaíba, dentre os quais destacam-se os seguintes projetos: LETOS (Baptista \& Meneguesso 1976), Três Marias (Menezes Filho et al. 1978), Bambuí Norte (Rabelo \& Santos 1979), Sondagens do Bambuí em Minas Gerais (Brandalise et al. 1980), Planoroeste (1981) e Radambrasil (1982).
A estratigrafia do Grupo Bambuí foi delineada a partir dos trabalhos fundamentais de Costa \& Branco (1961) e Dardenne $(1978,1979)$. Referente à caracterização e interpretação faciológica da Formação Sete Lagoas na área de pesquisa, cabe salientar os trabalhos de Beurlen (1973), Abreu-Lima (1997) e Nobre-Lopes (2002). Beurlen (op.cit.) realizou um detalhado estudo da geologia do município de Montalvânia, oferecendo informações de grande importância sobre as relações estratigráficas e estruturais desta unidade. Abreu-Lima (1997) estudou a Formação Sete Lagoas no norte de Minas Gerais (municípios de Lontra, Itacarambí e Montalvânia), a partir da descrição dos furos de sondagens executados pela CPRM no final da década de 70 (Brandalise et al. 1980). Por sua vez, Nobre-Lopes (2002) analisou, detalhadamente, as relações existentes entre as mineralizações de $\mathrm{Zn} / \mathrm{Pb}$ e as rochas encaixantes da Formação Sete Lagoas, na região de Januária-Itacarambi.

CONTEXTO GEOLÓGICO O vale do rio São Francisco, na região norte de Minas Gerais, exibe uma sucessão sedimentar constituída por coberturas neoproterozóica (Grupo Bambuí) e fanerozóicas (Grupo Urucuia e depósitos terciário-quaternários), pertencentes à Bacia Intracratônica do São Francisco (Alkmim \& MartinsNeto 2001). Tectonicamente, a área insere-se no compartimento central do Cráton do São Francisco (Almeida 1977, Alkmim \& Martins-Neto 2001) e, à exceção do extremo leste, onde foi observada influência dos dobramentos brasilianos da Faixa Araçuaí, a área representa uma cobertura tabular subhorizontal, pouco deformada na escala regional. No entanto, estruturas tectônicas de orientação NW (horst-anticlinal de Montalvânia, Beurlen 1973) e E-W (falha de São João das Missões) foram observadas em trabalhos de campo e a partir de fotolineamentos. De maneira geral, a estrutura da área de estudo está controlada pela disposição do embasamento. Este embasamento, coincidindo com o início da sedimentação do Grupo Bambuí, foi soerguido - Alto de Januária - provavelmente por ação de falhas normais sinsedimentares, que originaram subsidência diferencial, provocando um progressivo afundamento para todas as direções a partir da região de Januária (Iglesias 2007).

O rio São Francisco representa um divisor na distribuição e espessura das formações do Grupo Bambuí na área (vide Figuras 2 e 3). A falta de correspondência entre a margem esquerda, onde afloram as rochas carbonáticas da Fm. Sete Lagoas e a margem direita, representada pela sucessão pelito/carbonática das formações Serra de Santa Helena e Lagoa do Jacaré, foi relacionada por diversos autores (Robertson 1963, Cassedane 1972, Lopes 1979) a uma falha de gravidade (mascarada pelas extensas coberturas da planície aluvial do rio São Francisco), de direção NNE com rebaixamento do bloco da margem direita.

Eventos de reativação tectônica associados à abertura do Atlântico Sul (Cretáceo-Terciário), resultaram na sedimentação dos arenitos do Grupo Urucuia (Campos \& Dardenne 1997a), além de fraturamento generalizado, segundo as direções NE e NW, que vem condicionando 


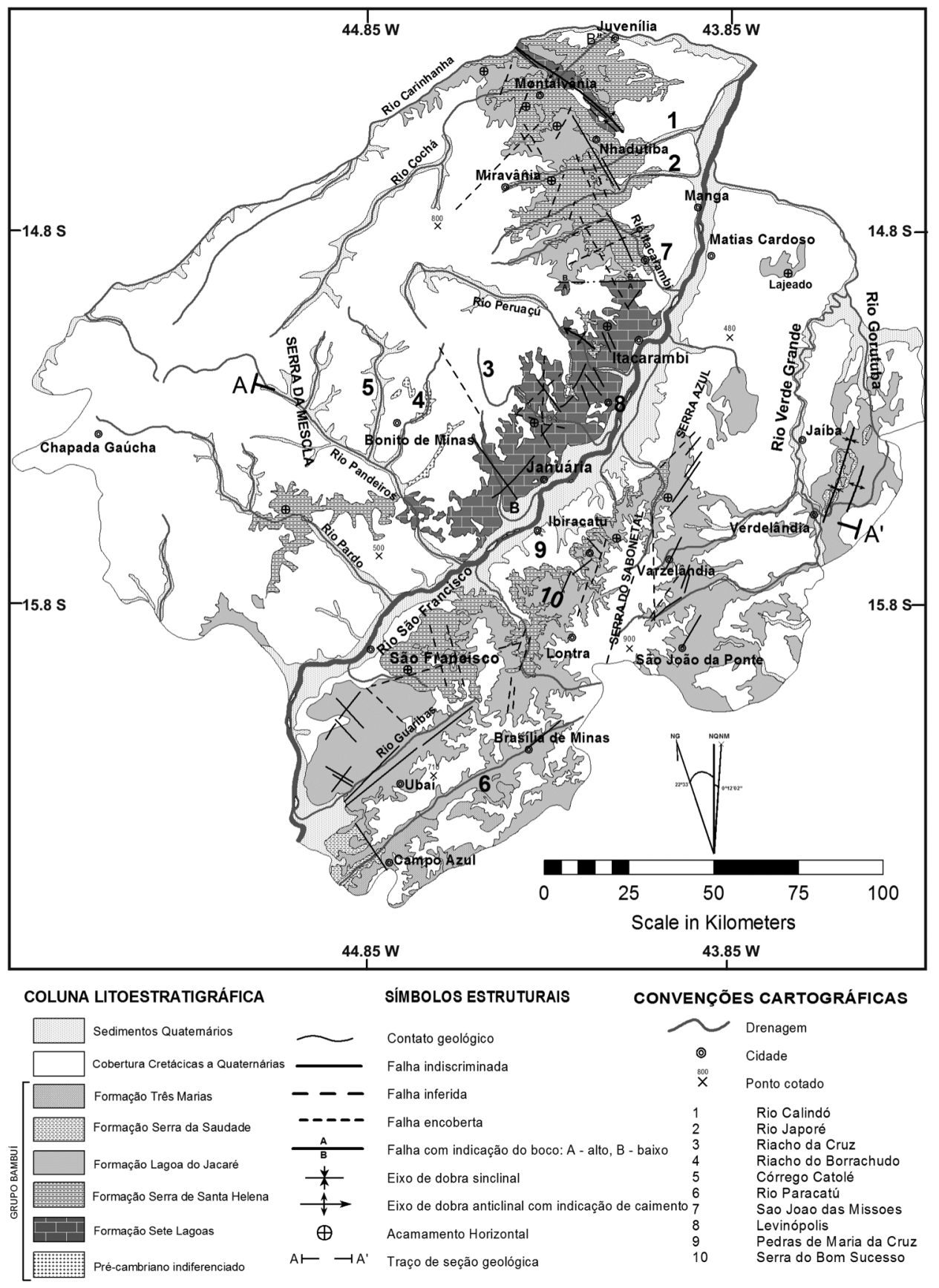

Figura 2 - Mapa geológico do vale do Rio São Francisco no norte de Minas Gerais (Iglesias 2007).

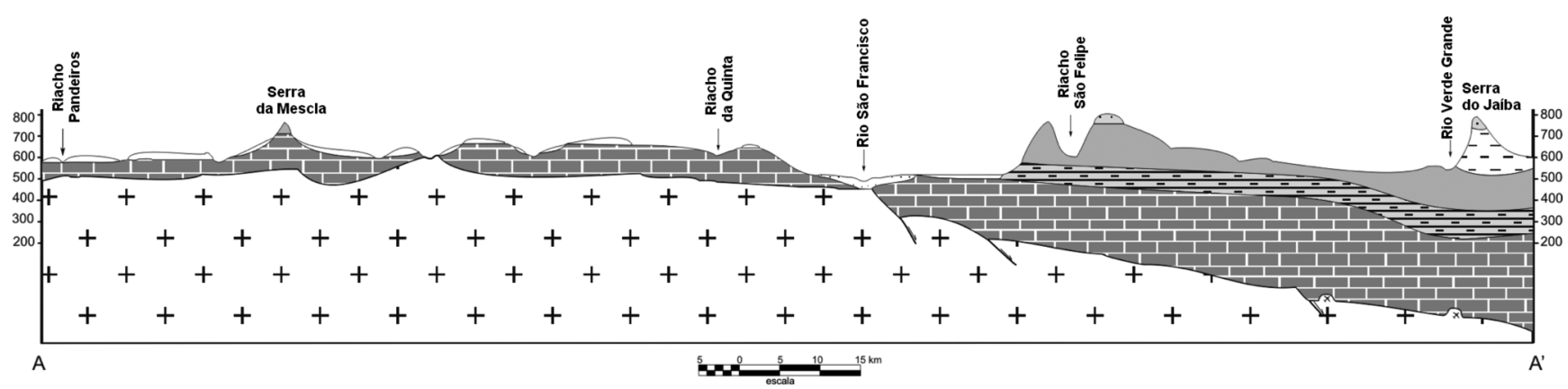

Figura 3 - Seção geológica esquemática NW-SE da área de estudo, entre a região de Bonito e a Serra do Jaiba, conforme Iglesias (2007) (ver localização no mapa geológico - figura 2). 
grande parte do sistema de drenagem da área.

\section{LITO-ESTRATIGRAFIA DO GRUPO BAM-} BUÍ O Grupo Bambuí (750-600 Ma) constitui a cobertura neoproterozóica de maior distribuição no Cráton do São Francisco. Representa associação de litofácies siliciclásticas e bioquímicas, na forma de sedimentos plataformais depositados em extenso mar epicontinental. Regionalmente, foram identificadas as formações clássicas do Grupo Bambuí, conforme definido no Projeto Radambrasil (1982), tendo por base, com modificações, a estratigrafia proposta por Costa \& Branco (1961) e Dardenne (1978). Na área, o Grupo Bambuí é constituído por duas (02) sucessões principais; a basal, marinha, composta da base para o topo, pelas formações Sete Lagoas (carbonática), Serra de Santa Helena (pelítico-carbonática), Lagoa do Jacaré (carbonática) e Serra da Saudade (pelítica), as quais compõem o Subgrupo Paraopeba; a sucessão de topo é marinho-continental e está representada pela Formação Três Marias, predominantemente psamítica. A figura 4 apresenta a coluna lito-estratigráfica sintética para o vale do rio São Francisco, no norte de Minas Gerais.

Formação Sete Lagoas A Formação Sete Lagoas (Costa \& Branco 1961) representa a unidade basal do Grupo Bambuí na área, sendo constituída por uma sucessão carbonática que aflora nas serras dos municípios de Januária e Itacarambi, na margem esquerda do rio São Francisco. À altura do vilarejo de São João das Missões a continuidade desta formação é interrompida por uma falha normal de direção E-W. A partir daí, e mais para o norte, a Formação Sete Lagoas só aflora ao longo de uma estreita faixa, segundo a direção NW, na região de Montalvânia, coincidindo com uma estrutura tectônica do tipo horst-anticlinal. As espessuras estimadas nas áreas aflorantes são de cerca de $200 \mathrm{~m}$. Já para sudeste e para norte, em direção às regiões de Lontra e Montalvânia, a espessura da formação atinge 330 e 500 $\mathrm{m}$, respectivamente, como evidenciado pelos furos estratigráficos 1-PSB-13MG e 1-PSB-14MG (Brandalise et al. 1980). Esta diferença de espessura, associada ao fato de as fácies sedimentares serem correlacionáveis com as que afloram na região de Januária-Itacarambi, conforme interpretação a partir dos testemunhos dos furos da CPRM por Abreu-Lima (1997), parece indicar que a sedimentação da Formação Sete Lagoas coincidiu com significativo evento de subsidência do embasamento. Assim, considera-se o Alto de Januária e depressões adjacentes como sin-sedimentares (Iglesias 2007). A figura 5 apresenta a disposição das curvas de isoespessuras para a Fm. Sete Lagoas, na área estudada.

LITOFÁCIES E AMBIENTES DE SEDIMENTA$C \zeta \tilde{A} O$ A Formação Sete Lagoas, na área, tem sido alvo de numerosas pesquisas (Cassedanne 1972, Beurlen 1973, Dardenne 1979, Lopes 1979, Abreu-Lima 1997, Nobre-Lopes 2002), relacionadas às mineralizações ( $\mathrm{Pb}-\mathrm{Zn}-\mathrm{Ag}-\mathrm{F})$ hospedadas nesta unidade. Através do levantamento de seções estratigráficas nas serras da

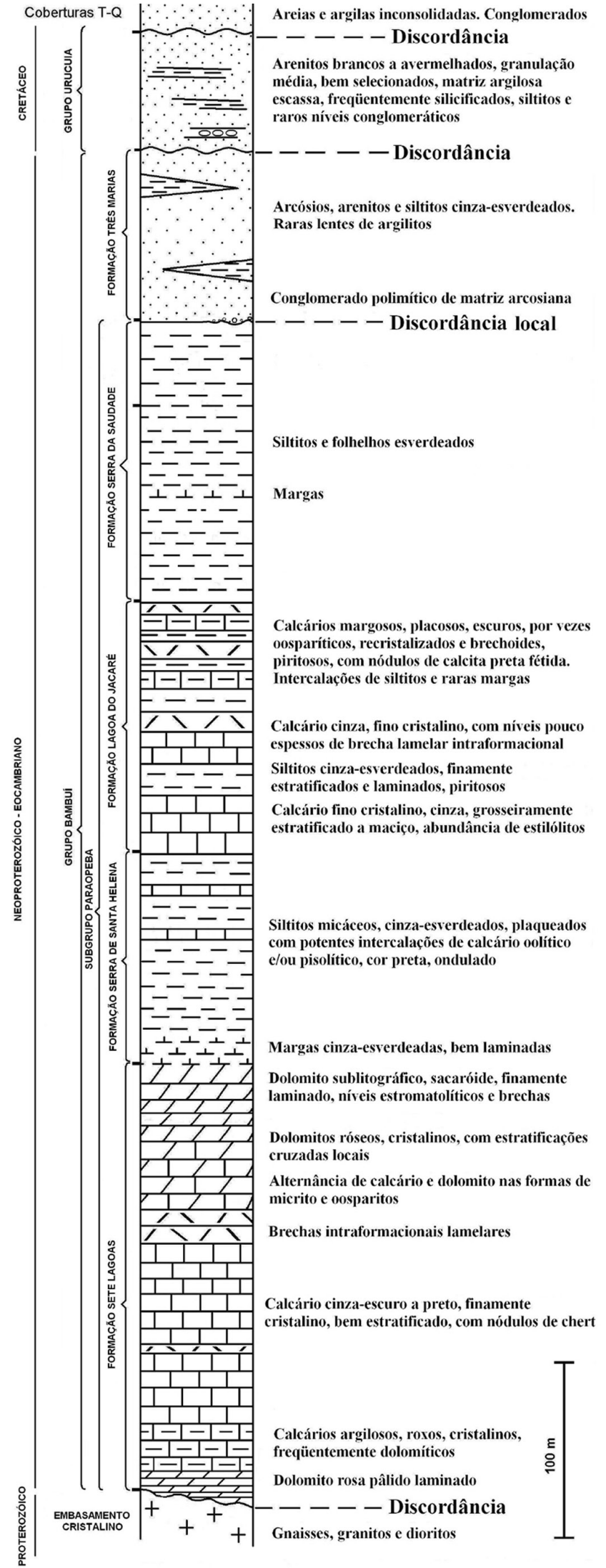

Figura 4 - Coluna lito-estratigráfica sintética do Grupo Bambui e coberturas fanerozóicas no vale do rio São Francisco (norte de Minas Gerais).

Mãe Joana e Cardoso de Minas (Januária - Itacarambi) foi possível reconhecer as diversas litofácies aflorantes. 


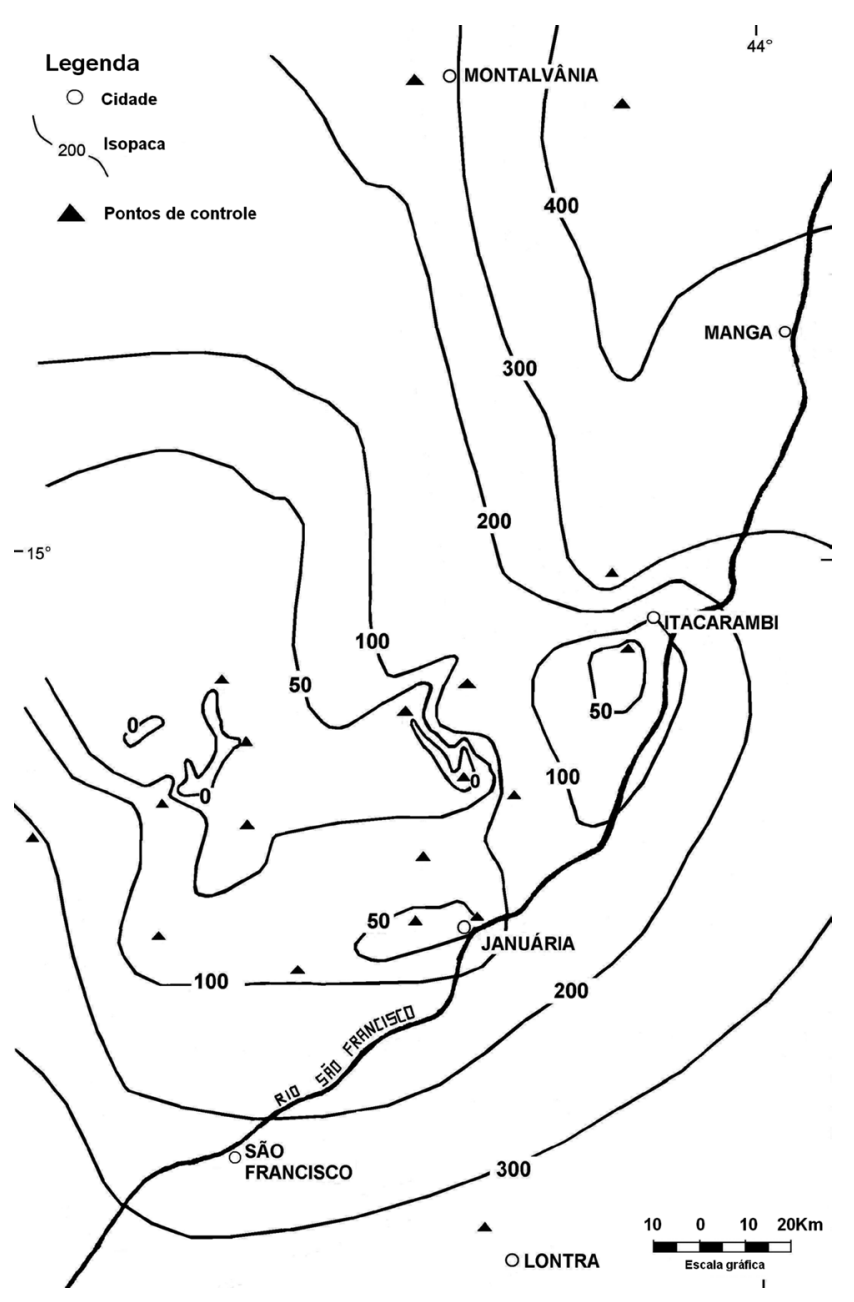

Figura 5 - Mapa de isópacas da Formação Sete Lagoas no vale do rio São Francisco (norte do Estado de Minas Gerais). Os triângulos representam pontos de controle, onde a espessura foi verificada por levantamento de seção, furos de sondagem ou poços tubulares (Iglesias, 2007).

A Fm. Sete Lagoas é composta por uma sucessão de calcários e dolomitos que, da base para o topo, pode ser individualizada em sete litofácies:

Litofácies 1 É representada por dolomito rosa pálido, laminado. Este nível mostra-se descontínuo e nas ocorrências mais representativas (Riacho da Cruz) exibe espessura de $5 \mathrm{~m}$.

Litofácies 2 É constituída por calcários argilosos, roxos, microcristalinos, frequentemente dolomíticos, finamente laminados, com os planos de estratificação sublinhados por filmes argilosos verdes. A espessura foi estimada em $20 \mathrm{~m}$.

Litofácies 3 É representada por calcários escuros, finamente cristalinos, bem estratificados $(5-40 \mathrm{~cm})$. São comuns horizontes com abundância de nódulos de chert preto e estilólitos e ainda estruturas como marcas onduladas, estratificações cruzadas e hummocky. Esta litofácies apresenta grande continuidade e sua espessura foi estimada em $80 \mathrm{~m}$.

Litofácies 4 É constituída por brechas intraformacionais lamelares (com intraclastos variando de 0,5 - 15 $\mathrm{cm}$ ) e matriz calcítica (cinza) ou magnesiana (rosa), formando ciclos gradacionais com intraclastos de tamanho maior na base e menores no topo, passando a seguir, geralmente, para laminações plano-paralelas. Sua espessura é de $15 \mathrm{~m}$.

Litofácies 5 É representada por calcarenitos dolomíticos rosados ou cinza-claros, oolíticos e, por vezes, intraclásticos. Os bancos são bem laminados e mostram freqüentes estratificações cruzadas. No local denominado Mina Grande (vilarejo próximo de Itacarambi) atinge sua espessura máxima de $30 \mathrm{~m}$.

Litofácies 6 É caracterizada por dolomito rosado, por vezes cinza, sacaróide, vacuolar, fortemente brechado e localmente oolítico, estromatolítico ou intraclástico. Apresenta-se estratificado em bancos espessos com estratificações cruzadas. No topo desta litofácies ocorre a maioria das mineralizações plumbo-zinzíferas exploradas na região. Sua espessura foi estimada em $50 \mathrm{~m}$.

Litofácies 7 É constituída por dolomito bege, sublitográfico, bem laminado, com presença de estruturas estromatolíticas e oolíticas. A espessura aproximada é de $30 \mathrm{~m}$.

Localmente, para o topo dessa unidade, aparecem níveis detríticos finos, representando contato gradual com os pelitos da formação superior.

A deposição das rochas carbonáticas da Fm. Sete Lagoas ocorreu em ambiente marinho raso, em resposta a uma importante transgressão marinha. Desenvolveram-se plataformas carbonáticas num contexto tectônico extensional, com altos e baixos sin-sedimentares. Quanto à interpretação das litofácies e sua organização em ciclos de sedimentação, Dardenne (1979) sugere que as unidades representam, pelo menos, um ciclo regressivo finalizado nos dolomitos rosa sacaroidais da litofácies 6. Abreu-Lima (1997) também define um único ciclo regressivo para toda a Formação Sete Lagoas. Para Nobre-Lopes (2002), a Fm. Sete Lagoas é composta por diversas sucessões do tipo shallowingupward, em que cada unidade é depositada em águas cada vez mais rasas.

Formação Serra de Santa Helena A Formação Serra de Santa Helena (Costa \& Branco 1961) constitui uma sucessão sedimentar predominantemente pelítica. Assenta-se sobre a Formação Sete Lagoas em contato concordante e gradativo, representado pelo aumento gradual do conteúdo de pelitos nos carbonatos de topo da Formação Sete Lagoas. A Formação Serra de Santa Helena apresenta ampla distribuição na área, aflorando na porção sul, constituindo a base das escarpas das serras do Sabonetal, do Bom Sucesso (Lontra) e de São 
Francisco, em uma faixa continua de mais de $130 \mathrm{Km}$ de extensão, que engloba altitudes situadas entre $505 \mathrm{~m}$ e $640 \mathrm{~m}$, o que perfaz uma espessura máxima de cerca de 135 m. Já na margem esquerda do rio São Francisco, esta unidade constitui a base das serras da região de Manga, Nhandutiba e Montalvânia.

\section{LITOFÁCIES E AMBIENTES DE SEDIMENTA-}

$C ̧ \tilde{A O}$ A Formação Serra de Santa Helena é composta por siltitos, folhelhos e margas de cores esverdeadas (arroxeados quando intemperizados) e ainda, intercalações métricas de calcário cinza escuro. Da base para o topo, a unidade representa uma sucessão de margas, finamente laminadas, que passam transicionalmente a siltitos finos, esverdeados, ricos em cristais de pirita, intercalados com lentes de calcário cinza, fétidos e plaqueados. O topo da formação é constituído por siltitos cinza esverdeados, micáceos, finamente laminados e piritosos. Quanto às estruturas sedimentares, os pelitos mostram estratificação e laminação plano-paralela. Localmente, as camadas se apresentam maciças, com espessuras da ordem de 10-15 cm. Marcas de onda e ripples foram observados em alguns afloramentos.

A Formação Serra de Santa Helena representa o afogamento gradual da plataforma carbonática da formação anterior e a deposição de uma sucessão em ambiente marinho plataformal, com profundidades variáveis, submetido, por vezes, a influência de ondas.

Formação Lagoa do Jacaré A Formação Lagoa do Jacaré (Costa \& Branco 1961) sobrepõe-se à Formação Serra de Santa Helena em contato gradacional. Dardenne (1978) utilizou a denominação de Formação Nhandutiba para os carbonatos correspondentes à Formação Lagoa do Jacaré na região do vale do rio São Francisco. Visando evitar a inserção de novos nomes que viriam confundir a nomenclatura estratigráfica regional, optouse pela manutenção da denominação original de Formação Lagoa do Jacaré (Branco \& Costa 1961). Esta unidade apresenta a maior distribuição dentre as formações do Grupo Bambuí na área de estudo. À exceção da região de Januária-Itacarambi (a sul da falha de São João das Missões), onde a unidade só foi preservada no topo do denominado Morro de Itacarambi, a área mapeada apresenta um grande número de afloramentos desta formação, destacando-se, de norte para sul, as serras de Nhandutiba, Matias Cardoso, Lajeado, Serra Azul, Sabonetal, Bom Sucesso (Lontra), y São Francisco, assim como os vales dos rios Paracatu e Guaribas. Em grande parte da região mapeada, a unidade representa o topo aflorante do Grupo Bambuí, em geral, erodida e recoberta por arenitos cretácicos. A espessura da Formação Lagoa do Jacaré atinge cerca de $140 \mathrm{~m}$ na serra do Sabonetal e $120 \mathrm{~m}$ na estrada que segue de São Pedro para Ibiracatu. Nas imediações do horst-anticlinal de Montalvânia a unidade varia, segundo o flanco, de 80 a 120 metros de espessura (Beurlen 1973).

LITOFÁCIES E AMBIENTESDE SEDIMENTAÇÃO A Formação Lagoa do Jacaré é composta por calcários pre- tos a cinza, localmente oolíticos e pisolíticos, brechas intraclásticas, margas e intercalações de siltitos e folhelhos de cor esverdeada. Os calcários apresentam-se em estratos paralelos, com espessura média compreendida entre 10 e $20 \mathrm{~cm}$, geralmente separados por pequenas superfícies onduladas. A intensa recristalização/neomorfismo, a presença de nódulos de chert e o cheiro fétido quando percutidos, são algumas das características destes calcários. Além das marcas onduladas, em toda a área constatou-se a presença de gretas de ressecamento, estratificações cruzadas e, esporadicamente, estruturas sugestivas de estratificações cruzadas por ondas (hummocky). Localmente, identificou-se estrutura estromatolítica do tipo colunar, nos calcários desta unidade, nas proximidades de São João da Ponte.

A sedimentação regressiva da Formação Lagoa do Jacaré sucedeu a formação anterior, constituindo nova fase de instalação de plataformas carbonáticas de alta energia, sujeita a constante retrabalhamento (brechas intraclásticas) e episódios de tempestades (hummocky), intercaladas com períodos de relativa calmaria. As gretas de ressecamento, observadas em vários locais, evidenciam a emersão de algumas partes da plataforma, provavelmente por curtos períodos de tempo. Outra das feições características da formação é a cor negra dos calcários e a abundância de pirita, que indicam condições de sedimentação redutoras e intensa atividade orgânica.

CARACTERIZAÇÃO PETROLÓGICA/PETROGRÁFICA DA FORMAÇÃO LAGOA DO JACARÉ NA REGIÃO DE LONTRA Foram levantados perfis representativos da formação ao longo da rodovia BR-135, na serra do Bom Sucesso, entre as localidades de Pedras Maria da Cruz e Lontra, com a finalidade de definir petrograficamente, pela primeira vez, esta formação na margem direita do rio São Francisco. Foram descritos em detalhe, amostrados e analisados petrograficamente, 140 metros da formação. A partir dos dados de campo e da análise de 22 lâminas delgadas foram identificados calcários e calcários dolomíticos, os quais apresentaram-se muito afetados diageneticamente, o que, às vezes, acarretou a perda de feições deposicionais. Estilolitização por compactação, dolomitização por substituição e/ou cimentação, silicificação e neomorfismo foram os principais eventos diagenéticos identificados.

Com base em estudos petrológicos/petrográficos, foram discriminados, da base para o topo, três litofácies, conforme a figura 6 :

Litofácies 1 - Calcarenitos e calcissiltitos neomorfizados Esta litofácies é representada por calcários cinza a cinza-escuro, bem estratificados, ondulados e, por vezes, truncados por possíveis estruturas hummocky. Frequentemente ocorrem horizontes de brecha intraclástica e nódulos de chert preto. Petrograficamente observouse que os calcários podem, eventualmente, ser dolomíticos, estando muito neomorfizados (Fig. 7C), variando sua cristalinidade de fina a média. Microestilólitos em rede ocorrem paralelos à estratificação e contém matéria carbonosa e óxido de ferro associados. Mediante a 
técnica de Folk (inserção de cartolina entre o foco de luz e a lâmina) evidenciou-se a presença de numerosos vestígios aloquímicos (Fig. 7D), associados a possíveis pelóides e grãos compostos, tendo, em média, tamanhos compreendidos na fração silte/areia fina a areia média $(0,03$ a $0,9 \mathrm{~mm})$. A litofácies representa os primeiros 60 $\mathrm{m}$ da unidade.

Litofácies 2 - calcários impuros Esta litofácies constitui pacote de calcários impuros, de cor rosada, que, em campo, mostram aspecto semelhante às margas. As estruturas observadas foram principalmente laminações cruzadas e deformação por tectonismo. Intercalados ocorrem siltitos cinza esverdeados, por vezes calcíferos e plaqueados, com laminações truncadas e estruturas de carga. Petrograficamente, observa-se que o calcário apresenta-se fortemente neomorfizado, com aspecto sujo e abundância de grãos de quartzo (>10\%) na granulação silte, imersos em matriz argilosa, fortemente oxidada (Fig. 7B). A espessura foi estimada em $25 \mathrm{~m}$.

Litofácies 3 - siltitos e calcissiltitos Esta litofácies constitui o topo da seção. É composta por espessos pacotes de siltitos, de cores esverdeadas (amarelos ou avermelhados quando alterados), finamente estratificados, plaqueados quando calcíferos e muito piritosos. Subordinadamente, lentes métricas de calcário, por vezes intraclásticos (Fig. 7A), similares aos da litofácies 1 , ocorrem intercaladas nos siltitos. Os vestígios de aloquímicos destes calcários mostram tamanhos menores do que os das litofácies anteriores. Observa-se ainda níveis centimétricos de arenito quartzoso fino, e níveis milimétricos de material carbonoso. Os siltitos são de granulação silte grosso, exibem laminações cruzadas, pequenas dobras de slumping e estrias de escorregamento. A espessura da litofácies é de 50 metros.

A ausência de vestígios de oólitos entre os aloquímicos e a grande contribuição terrígena que mostra a seção levantada em Lontra contrasta, notavelmente, com as seções descritas para esta formação por Costa \& Branco (1961), no sul da Bacia do São Francisco, Beurlen (1973), na região de Montalvânia e Dardenne (1978), na região de Nhandutiba. Esta variação faciológica poderia indicar condições de sedimentação em sub-ambientes diferenciados, no contexto de uma plataforma carbonática, caracterizado por menor energia.
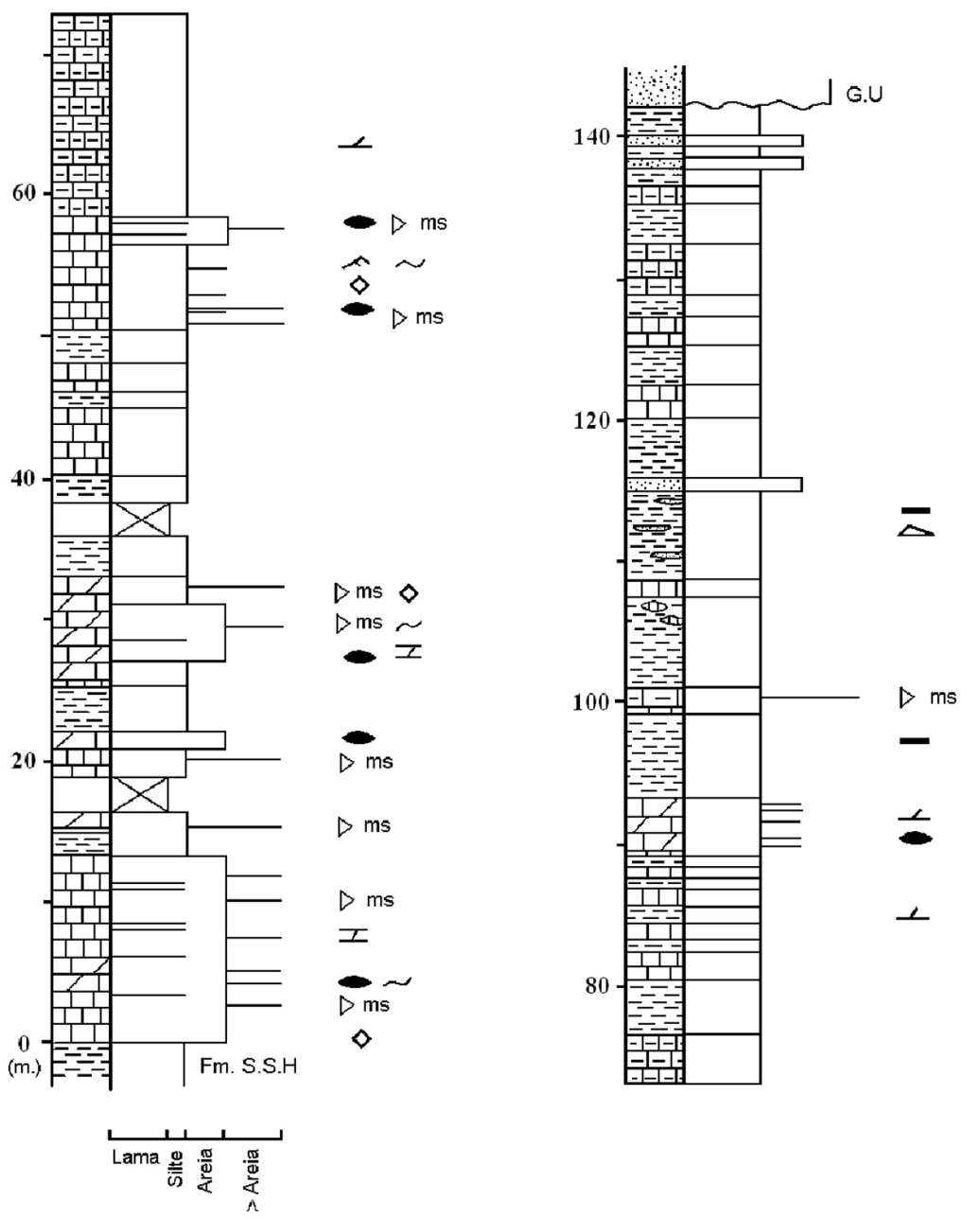

\section{Legenda}

$\diamond$ Cristais de pirita

D ms Brecha matriz suportada

- Lente silicosa

M Marcas onduladas

工 Estratificação cruzada planar

- Laminação cruzada

A Climbing ripples

- Material carbonoso

Astratificação lenticular

Calcário neomorfizado

TH Calcário dolomítico

neomorfizado

星-⿹ Calcário impuro

neomorfizado

E-7 Siltito

Arenito

Trecho sem descrição

Fm. S.S.H: Formação Serra

de Santa Helena

G.U: Grupo Urucuia

Figura 6 - Coluna estratigráfica de detalhe da Formação Lagoa do Jacaré, ao longo da rodovia BR-135, entre as localidades de Pedras Maria da Cruz e Lontra/MG (Iglesias, 2007). 

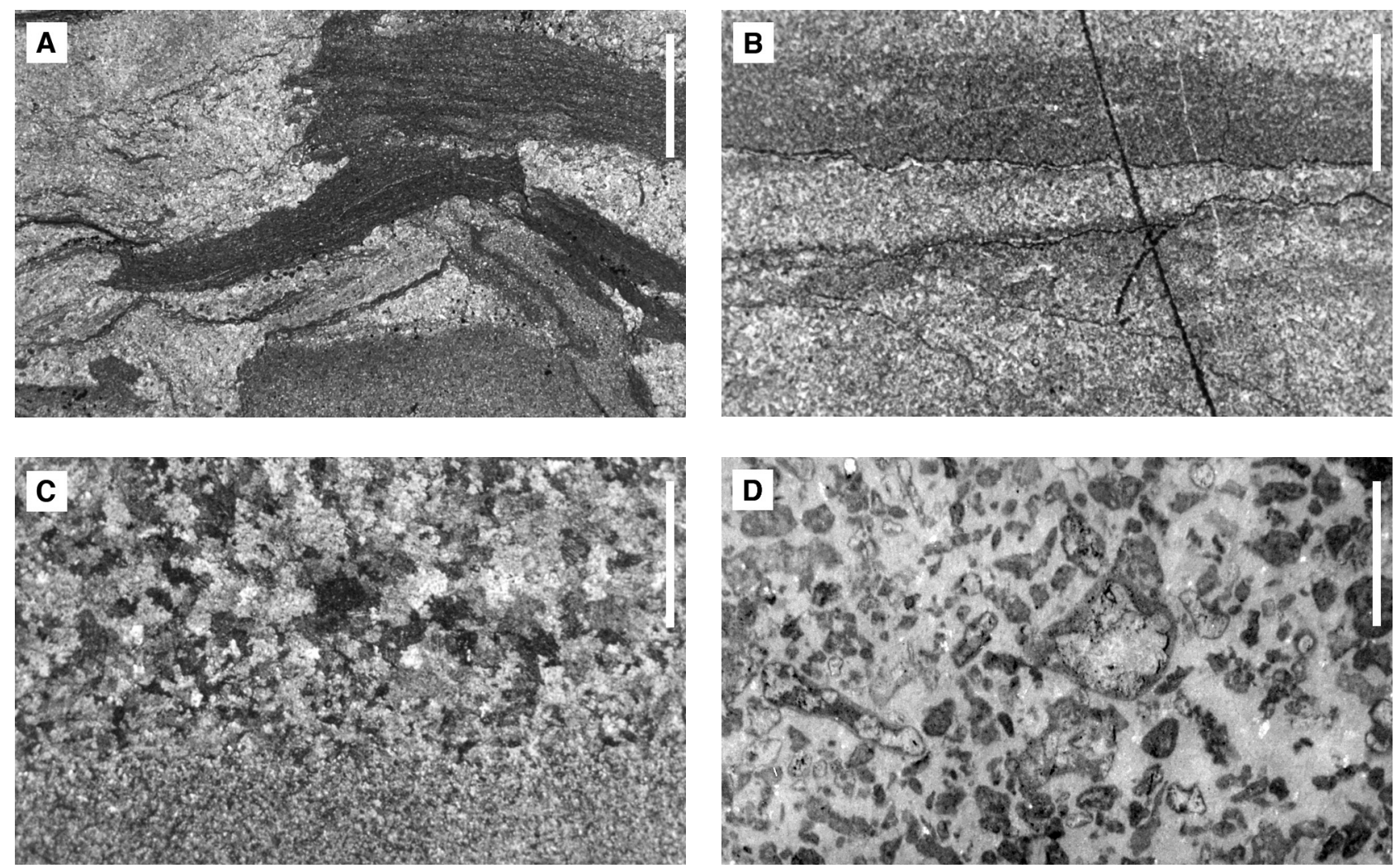

Figura 7 - Seqüência de fotomicrografias mostrando feições petrográficas dos calcários da Fm. Lagoa do Jacaré na região de Lontra. (A) Brecha intraclástica lamelar da litofácies 3, com evidências de deformação tectônica. Nicóis cruzados (NX). A barra branca representa $3 \mathrm{~mm}$. (B) Estilólitos em calcário neomorfizado da litofácies 2. NX. A barra branca representa $4 \mathrm{~mm}$. (C) Mosaico pseudoesparítico em calcário neomorfizado da litofácies 1. Notar a diminuição no tamanho dos cristais para o topo. NX. A barra representa 1,7 mm. (D) Vestígios de aloquímicos, tamanho areia muito fina, em calcarenito intraclástico (litofácies 1), observados mediante a técnica de Folk. Nícois paralelos. A barra branca representa 0,17 mm.

Formação Serra da Saudade A Formação Serra da Saudade (Costa \& Branco 1961, Dardenne 1978) sobrepõe-se em contato concordante e gradacional à Formação Lagoa do Jacaré. Esta unidade é representada por conjunto predominantemente pelítico. A distribuição da Fm. Serra da Saudade na área é restrita, concentrando-se principalmente na margem direita do rio Verde Grande, próximo à cidade de Verdelândia, na encosta inferior da Serra do Jaíba, onde apresenta espessura de $100 \mathrm{~m}$. Também aflora no vale do rio Paracatu, nas imediações da cidade de Campo Azul, com cerca de $60 \mathrm{~m}$ de siltitos que ocorrem sotopostos aos arenitos da Fm. Três Marias e sobrepostos a calcários rítmicos (calcarenito/calcilutito) de aspecto noduloso. A existência dos afloramentos desta unidade na serra do Jaíba representa uma exceção, possivelmente devido ao fato de coincidir com uma estrutura sinclinal de grandes proporções, que preservou da erosão as formações Serra da Saudade e Três Marias.

LITOFÁCIES E AMBIENTES DE SEDIMENTA$C ̧ \tilde{A} O$ A Formação Serra da Saudade é constituída por sucessão de siltitos, siltitos argilosos e folhelhos de cor esverdeada (amarelos, quando intemperizados) finamente laminados. Estudos petrográficos mostram que a laminação obedece a alternância milimétrica de níveis sílticos ricos em grãos de quartzo e níveis argilosos. Nos afloramentos da serra do Jaíba os siltitos se apresentam levemente foliados, mostrando xistosidade incipiente, atestando a influência dos dobramentos da Faixa Araçuaí (Iglesias 2007, Iglesias \& Uhlein 2008).

A deposição da Fm. Serra da Saudade esta relacionada a rápida transgressão marinha, que modificou as condições responsáveis pela deposição da Formação Lagoa do Jacaré, evoluindo para ambiente mais profundo e de águas calmas, que originou as finas laminações verificadas nos siltitos. A deposição da formação ocorreu provavelmente em contexto plataformal com influência de correntes de turbidez e episódios de tempestades (Uhlein et al. 2004).

Formação Três Marias A Fm. Três Marias repousa sobre o Subgrupo Paraopeba, em contatos variados: gradativo e transicional quando o contato é com Fm. Serra da Saudade, no extremo sul da área, e erosivo e discordante no caso do contato com os calcários sobrepostos aos siltitos da Fm. Serra da Saudade na serra do Jaíba. Neste último local, observou-se a existência 
de delgados conglomerados polimíticos de matriz arcosiana silicificada e clastos de calcário, constituindo a base da Fm. Três Marias. Na serra do Gorutuba (fora da área), os conglomerados podem atingir até 15 metros de espessura (Costa 1978). A espessura da Formação Três Marias, nos locais estudados, não excedeu $100 \mathrm{~m}$.

LITOFÁCIES E AMBIENTES DE SEDIMENTA$C \zeta \tilde{A} O$ A Formação Três Marias, na área, é representada por um conjunto de arcósios, arenitos e siltitos, de cores verde a cinza-esverdeado, contendo raras lentes de argilitos. Na serra do Jaíba os arcósios, apresentam-se como cinza-esverdeados, de granulação média a grossa, calcíferos, ocorrendo em bancos maciços, mostrando estratificação cruzada. Os arcósios são constituídos predominantemente por grãos de quartzo, K-feldspato e plagioclásio imersos em matriz siltosa e micácea. Já na região sul da área (municípios de Ubaí, Campo Azul), a Fm. Três Marias apresenta-se como siltitos cinza-esverdeados, com camadas lenticulares de arenito fino, feldspático e calcífero, que transiciona lateral e verticalmente para arenitos arcosianos marrom-avermelhados.

O estudo da unidade permitiu a interpretação de que a Formação Três Marias depositou-se em um contexto de borda de bacia, com espessuras aumentando para SW, diferentemente das unidades inferiores, como as formações Sete Lagoas, Serra de Santa Helena e Lagoa do Jacaré, que mostram espessamento para leste. Pode-se concluir, portanto, que os depocentros locais das formações inferiores e médias do Grupo Bambuí são diferentes do depocentro da Fm. Três Marias.

A sedimentação desta unidade ocorreu após a deposição da Fm. Serra da Saudade, a partir de uma significativa regressão, com predomínio de ambiente plataformal sob ação de ondas de tempestades a sudoeste (Chiavegatto 1992, Uhlein et al. 2004), evoluindo para ambiente continental a transicional (flúvio-deltaico) para nordeste, como indicam as estratificações cruzadas, acanaladas e sigmoidais reconhecidas por Chiavegatto et al. (2003) e Iglesias \& Uhlein (2008), nos arenitos e arcósios da Serra do Jaíba.

GRUPO URUCUIA Sob a denominação Grupo Urucuia (Barbosa 1965) foram englobados, neste trabalho, todos os sedimentos cretáceos que ocorrem dentro dos limites da área, inclusive os delgados conglomerados e siltitos da seqüência basal que, em alguns mapeamentos anteriores, foram relacionados como pertencentes ao Grupo Areado (Ladeira \& Brito 1968). No entanto, não foram observadas no campo diferenças significativas que justificassem tal separação. Discordante sobre as formações inferiores, podendo assentar-se sobre quaisquer delas, o Grupo Urucuia ocorre em extensa área, concentrando-se principalmente nos chapadões $(600-800 \mathrm{~m})$ a oeste do rio São Francisco. Salienta-se nesta área a serra da Mescla e os chapadões das cabeceiras dos córregos Catolé e Borrachudo, que mostram espessuras de até $80 \mathrm{~m}$. Mais a oeste, na região da serra das Araras, informações obtidas a partir de poços tubulares evidenciaram espessuras que chegam a atingir 250 metros. Já do outro lado do rio, o Grupo Urucuia constitui faixa de mais de $50 \mathrm{Km}$ de comprimento, desde São João da Ponte, que se acunha para o norte, até desaparecer no extremo setentrional da serra do Sabonetal. A espessura máxima constatada nesta região foi 170 m na Fazenda Santo Antônio da Boa Vista (Rabelo \& Santos 1979).

LITOFACIES E AMBIENTES DE SEDIMENTAÇÃO O Grupo Urucuia é constituído predominantemente por arenitos quartzosos, avermelhados e brancos, de granulação fina a média, com grãos arredondados, bem selecionados e matriz argilosa escassa. Os arenitos se apresentam freqüentemente compactos, muito silicificados, exibindo fratura conchoidal quando percutidos. Em alguns locais, na base da unidade, observou-se a existência de argilitos, siltitos e finos conglomerados monomíticos.

Microscopicamente os arenitos Urucuia são constituídos por grãos de quartzo, imersos em matriz de calcedônia impregnada de óxidos de ferro. A granulometria é razoavelmente uniforme, estando a maioria dos grãos compreendida entre silte e areia fina, sendo que o quartzo exibe, às vezes, extinção ondulante. Como minerais acessórios aparecem zircão e turmalina subarredondados, palhetas de muscovita e grãos de hidróxido de ferro.

As rochas descritas, estruturas sedimentares e o estudo faciológico efetuado por Campos e Dardenne (1997b) permitiram relacionar a sedimentação do Grupo Urucuia a um sistema eólico-fluvial. Algumas das evidências que confirmam este ambiente deposicional são a disposição dos arenitos em estratos cruzados tabulares e acanalados, a presença de conglomerados, os grãos sub-esféricos, o ótimo selecionamento e a escassa matriz argilosa.

COBERTURAS TERCIÁRIO-QUATERNÁRIAS As coberturas cenozóicas são unidades com uma grande distribuição na área, resultado dos intensos processos erosivos que afetaram as formações estudadas. Apresentam-se geralmente inconsolidadas, com espessuras variáveis e podem ser classificadas como coberturas aluvionares, coluvionares e eluvionares.

Coberturas aluvionares Distribuem-se em faixas de até $15 \mathrm{~km}$ de largura ao longo dos rios São Francisco, Verde Grande e seus principais tributários. São caracterizadas por depósitos resultantes do retrabalhamento fluvial recente, de materiais detríticos diversos. Sua espessura é muito variável, podendo alcançar até 40 metros na estrada que segue de Pedras Maria da Cruz para Lontra. Estas coberturas são constituídas, de maneira geral, por areias brancas, amareladas, com grãos angulosos a arredondados, leitos conglomeráticos, argilas e raras concreções calcárias. Em alguns locais, nas barrancas do rio São Francisco, exibem estratificações cruzadas e acamamento gradacional.

Coberturas coluvionares São resultantes de pequenos retrabalhamentos das unidades fanerozóicas e da regressão de formas de relevo tabular elevado (mesetas, 
tabuleiros, etc.). São constituídas por areias vermelhas ou esbranquiçadas e, ainda, elevada proporção de argila.

Coberturas eluvionares Correspondem às areias e argilas inconsolidadas, que se desenvolvem a partir da decomposição dos materiais rochosos subjacentes. No caso das areias provenientes do Grupo Urucuia, os materiais são representados por depósitos in situ ou pouco retrabalhados, que atingem espessuras da ordem de 20 a $30 \mathrm{~m}$. Distribuem-se nas extensas chapadas da área e freqüentemente apresentam forte lateritização. Os depósitos eluvionares gerados a partir da decomposição dos calcários e pelitos do Grupo Bambuí são constituídos predominantemente por argilas avermelhadas, com espessuras pequenas, da ordem de poucos metros. Geralmente, estes depósitos ocorrem associados a áreas de intensa carstificação.

CONSIDERAÇÕES FINAIS Através de mapeamento geológico de escala regional foi possível definir a estratigrafia do Grupo Bambuí na região norte de Minas Gerais. Na área pesquisada, estão representadas as cinco formações clássicas do Grupo Bambuí, compreendendo, da base para o topo, as formações Sete Lagoas (carbonática), Serra de Santa Helena (pelito-carbonática), Lagoa do Jacaré (carbonática), Serra da Saudade (pelítica) e Três Marias (psamítica). O Alto de Januária, importante feição de arqueamento positivo situado no centro da bacia Bambuí, é considerado como sin-sedimentar, contemporâneo à sedimentação da Formação Sete Lagoas. Mapa de isópacas para a Formação Sete Lagoas sugere diferentes valores de espessura para a unidade, fato este relacionado a sedimentação em provável contexto extensional. A deposição do Grupo Bambuí ocorreu em ambiente marinho plataformal com sucessivas transgressões e regressões. A base do Grupo Bambuí (Formação Sete Lagoas) mostra sedimentação em contexto extensional, enquanto que o topo (Formações Serra da Saudade e Três Marias) representa sedimentação em contexto compressivo (bacia de ante-país ou foreland). Diferentes depocentros foram identificados na área mapeada, sugerindo diferentes contextos bacinais. Cobrindo discordantemente as rochas do Grupo Bambuí, ocorrem arenitos quartzosos, bem selecionados, de idade cretácea, pertencentes ao Grupo Urucuia. Coberturas terciárias e quaternárias ocorrem em grande quantidade, principalmente na calha aluvionar do rio São Francisco.

Agradecimentos Este artigo é resultado de projeto de pesquisa apoiado pelo CNPq CT-Hidro 503.146/2003: Investigação Hidrogeológica do flúor em aqüíferos carbonáticos do Médio São Francisco, $M G$, e epidemiologia da fluorose dentária associada, coordenado pela professora.Leila Menegasse Velásquez (UFMG) e do projeto de Pesquisa FAPEMIG CRA772/05: Estratigrafia, sedimentologia e recursos minerais do Grupo Bambuí, Minas Gerais, coordenado pelo profesor Alexandre Uhlein (UFMG). Os autores são gratos, pelo apoio e ajuda financeira, às seguintes instituições: IGC/ UFMG, CAPES, MAE-AECI, CNPq, FAPEMIG. Os autores são especialmente gratos à Dra. Jane NobreLopes (CPRM-RJ) pelo grande interesse científico, valiosas sugestões e colaboração na petrografia de carbonatos. Agradecem também aos revisores anônimos da RBG pelas sugestões.

\section{Referências}

Abreu Lima S.A. 1997. Fácies, ambiente deposicional e aspectos diagenéticos das rochas carbonáticas da Formação Sete Lagoas na região norte de Minas Gerais, Bacia do São Francisco. Dissertação de Mestrado. Escola de Minas/UFOP, Ouro Preto, 121p.

Alkmim F.F \& Martins-Neto M.A. 2001. A bacia intracratónica do São Francisco: Arcabouço estrutural e cenários evolutivos. In: Pinto C.P. \& Martins-Neto M.A. (eds). Bacia do São Francisco: geologia e recursos naturais. SBG-MG, Belo Horizonte, p. 9-30.

Almeida F.F.M. de 1977. O Cráton do São Francisco. Revista. Brasileira de Geociências, 7(4):349-364.

Barbosa O. 1965. Série Bambuí. In: SBG, Congr. Bras. Geol., 19, Rio de Janeiro, Anais, 15p.

Baptista M.B. \& Meneguesso G. 1976. Projeto Leste do Tocantins-Oeste do São Francisco (LETOS), Folha Januária. DNPM/CPRM, Rio de Janeiro, 10v.

Beurlen H. 1973. Ocorrências de chumbo, zinco e fluorita nas rochas sedimentares do Precambriano Superior no Grupo Bambui em Minas Gerais (Brasil Central). Tese de doutoramento (tradução do autor), Faculdade de Ciências Naturais, Universidade Karl Ruprecht, Heilderberg, Alemanha, 165p.
Brandalise L.A., Pimentel G.B., Steiner H.P., Soares J., Mendes J.R., Queiroz N.F., Lima O.M., Pádua W. de. 1980. Projeto sondagens Bambuí em Minas Gerais: relatório final. Belo Horizonte, DNPM/CPRM, v.5.

Campos J.E.G \& Dardenne M.A. 1997b. Estratigrafia e sedimentação da Bacia Sanfranciscana: uma revisão. Rev. Bras. Geoc., 27(3):257-282.

Campos J.E.G \& Dardenne M.A. 1997a. Origem e evolução tectônica da Bacia Sanfrasciscana. Rev. Bras. Geoc., 27(3):283-294.

Cassedanne J. 1972. Catalogue descriptif des gîtes de Plomb e du Zinc du Brésil. Tese de Doutoramento. Sciencies Naturelles, Department de Geologie et Mineralogie, Université de Clermond-Ferrand, França.

Chiavegatto J.R.S. 1992. Análise estratigráfica das seqüencias tempestíticas da Formação Três Marias (Proterozóico Superior), na porção meridional da Bacia do São Francisco. Dissertação de Mestrado, Departamento de Geologia, Escola de Minas, Universidade Federal de Ouro Preto, 216p.

Chiavegatto J.R.S., Gomes N.S., Dardenne M.A., Delgado C.E.R. 2003. Estratigrafia do Grupo Bambuí nas regiões do Norte de Minas Gerais: Uma nova unidade estrati- 
gráfica em um contexto de inversão de bacia. In: SBG, Simpósio de Geologia de Minas Gerais, 12, Ouro Preto, 2003. Anais, CD rom (1 vol).

Costa M.T. \& Branco J.J.R. 1961. Introdução. In: Branco J.J.R. (ed.) Roteiro para a excursão Belo Horizonte Brasília. In: SBG, Congr. Bras. Geol., 14, Belo Horizonte, Anais, 15:1-119.

Costa P.C.G. 1978. Geologia das Folhas de Januária, Mata do Jaiba, Japoré e Manga, Minas Gerais. Memória Técnica, CETEC, Belo Horizonte.

Dardenne M.A.1978. Síntese sobre a estratigrafia do Grupo Bambuí no Brasil Central. In: SBG, Congr. Bras. Geol., 30, Recife, Anais, v. 2, p. 507-610.

Dardenne M.A. 1979. Les mineralizations de plomb, zinc, fluor du Proterozoique Superieur dans le Brésil central. Tese de doutoramento, Université de Paris VI (Pierre et Marie Curie), França.

Iglesias M. 2007. Estratigrafia e tectônica do Grupo Bambuí no norte do Estado de Minas Gerais. Dissertação de Mestrado, Instituto de Geociências, UFMG, Belo Horizonte, $121 \mathrm{p}$.

Iglesias M. \& Uhlein A. 2008. Estratigrafía do Grupo Bambuí na Serra do Jaíba, norte de Minas Gerais. Geonomos 16(1):21-27.

Iglesias M., Menegasse L.N, Fantinel L.M, Uhlein A., Rodrigues P., Mello S. (submetido). Influencia de los factores geológicos e hidrogeológicos en las altas concentraciones naturales de fluoruro en las aguas subterráneas del Grupo Bambuí (Neoproterozóico), norte del Estado de Minas Gerais (Brasil). Boletín Geológico y Minero de España.

Ladeira E.A \& Brito O.E.A. 1968. Contribuição à geologia do planalto da Mata da Corda. In: SBG, Congres. Bras. Geol., 22, Belo Horizonte, Anais, 1:181-199.

Lopes O.F. 1979. Minéralization em plomb, zinc et fluorine encaissées dans le Group Bambuí, du Proterozoïque Su- périeur de la region d'Itacarambi (Minas Gerais, Brésil). Tese de doutoramento. Université Pierre et Marie Curie, Paris IV, Paris, 190p.

Menezes Filho N.R., Matos G.M.M., Ferrari P.G. 1978. Projeto Três Marias. Belo Horizonte. DNPM/CPRM, 339p.

Nobre-Lopes J. 2002. Diagenesis of the dolomites hosting $\mathrm{Zn/Ag}$ mineral deposits in the Bambui Group at Januária region- $M G$. Tese de doutoramento, Unicamp, Campinas, $183 \mathrm{p}$.

PLANOROESTE. 1981. II plano de desenvolvimento integrado do noroeste mineiro. CETEC. Belo Horizonte.

Rabelo A.E.K. \& Santos A.V.L. dos. 1979. Considerações sobre a geologia regional da área norte-noroeste do Estado de Minas Gerais, Projeto Bambuí Norte, METAMIG. Relatório.

RADAMBRASIL. 1982. Folha SD.23. Brasília. Rio de Janeiro, DNPM, 660p.

Robertson J.F. 1963. Geology of the Lead-Zinc deposits in the município of Januária, state of Minas Gerais, Brazil. U.S. Geological Survey Bulletin, 1110-B:110.

Uhlein A., Lima O.N.B., Fantinel L.M., Baptista M.C. 2004. Estratigrafia e evolução geológica do Grupo Bambuí, Minas Gerais (Roteiro Geológico). In: SBG, Congr. Bras. Geol., 42, Araxá, Anais, CD-Rom (1 vol).

Velásquez L.N.M., Fantinel L.M., Ferreira E.F., Castilho L.S., Uhlein A., Vargas A.M.D., Aranha P.R.A. 2006. Fluorose dentária e anomalias de flúor na água subterrânea no município de São Francisco - Minas Gerais, Brasil. In: Silva C.R., Figueiredo B.R., Capitani E.M.de, Cunha F.G. da. 2005 (eds.) Geologia Médica no Brasil. Workshop Internacional de Geologia Médica, CPRM Serviço Geológico do Brasil, Rio de Janeiro, 110-117p.

Manuscrito ID 9918

Submetido em 10 de dezembro de 2007 Aceito em 20 de junho de 2009 